\title{
Research on the Elderly Education Model Based on Autonomous Learning Groups under the Regular Situation of COVID-19 Epidemic Prevention and Control
}

\author{
Xianwei Xia1, Hong $\mathrm{Yu}^{2}$ \\ ${ }^{1}$ Zhejiang Radio \& TV University, Hangzhou, China \\ ${ }^{2}$ Zhejiang Business Technology Institute, Ningbo, China \\ Email:xiaxianwei1989@163.com
}

How to cite this paper: Xia, X.W. and Yu, H. (2020) Research on the Elderly Education Model Based on Autonomous Learning Groups under the Regular Situation of COVID-19 Epidemic Prevention and Control. Open Access Library Journal, 7: e6861. https://doi.org/10.4236/oalib.1106861

Received: September 25, 2020 Accepted: September 27, 2020

Published: September 30, 2020

Copyright $\odot 2020$ by author(s) and Open Access Library Inc.

This work is licensed under the Creative Commons Attribution International License (CC BY 4.0).

http://creativecommons.org/licenses/by/4.0/

\begin{abstract}
In the face of the sudden outbreak of COVID-19 epidemic, offline learning for elderly education across the country was forced to stop. The school running units of elderly education have to transfer teaching from offline to online, and start to explore the online education model for the elderly. In this context, the autonomous learning model has gradually attracted attention. This paper discusses the educational needs of the elderly, the development trend of elderly education in the world and the characteristics of autonomous learning groups for the elderly. It also analyzes the difficulties faced by the elderly education under the regular situation of COVID-19 epidemic prevention and control and finally proposes the development path of the elderly education based on the autonomous learning groups.
\end{abstract}

\section{Subject Areas}

Education

\section{Keywords}

Elderly Education, Autonomous Learning Groups, Online Learning

\section{Introduction}

By the end of 2018, there were more than 62,000 universities and schools for the elderly at all levels in China, with more than 8 million students [1]. In the face of the sudden outbreak of COVID-19 epidemic, schools all over the country were 
forced to postpone the opening of school, and traditional classroom learning could not continue for the time being. Universities and community colleges for the elderly, which carry out education activities for the elderly, cannot play their due role during the epidemic period. Compared with the "suspension of classes but no suspension of learning" of primary and secondary students, the education for the elderly was in a "stagnant state". Although some educational institutions for the elderly tried to carry out "online teaching", it has not achieved the expected results, regardless of the scale, degree of participation and school running effect. In the face of the new situation of COVID-19 epidemic prevention and control, it is urgent to explore a new elderly education model, which is suitable for China's national conditions and can protect the learning right of the elderly. Based on the educational needs of the elderly learners and from the perspective of autonomous learning groups, this paper explores an elderly education model adapting to the new situation.

\section{Characteristics and Educational Needs of the Elderly Learners}

With regard to the study of elderly learners, McClusky, the father of Gerontology and honorary professor of the University of Michigan, discusses the educational needs of the elderly from five aspects: coping needs, expressive needs, contribution needs, influence needs and self transcendence needs, and puts forward the theory of demand [2]. At the bottom of the learning needs of the elderly, McCluskey set up health, law and other related learning, which is similar to Londoner's theory that the learning of the elderly should be based on the needs of means (Language and computer, etc.) or survival needs [3]. That is to say, for the elderly learners, it is not easy to carry out recreational leisure activities, but requires learning to meet the needs of basic life. And, the top priority of McClasky's theory is the demand of transcendence, that is, the need to transcend the limitations of life. As the characteristics of the actual existence of the elderly, we can see the reality of old age and death. Therefore, on the one hand, the elderly learners pursue learning to meet the basic life; on the other hand, they pursue learning beyond life. In addition, Wei Huijuan, a scholar in Taiwan, based on the demand range theory, constructed a four-level model of elderly education curriculum, including basic curriculum (i.e. to meet the needs of coping), interest curriculum (expressive needs curriculum), contribution impact curriculum (i.e. service demand, influence demand curriculum) and transcendence curriculum (i.e. self-transcendence curriculum) [4]. This model curriculum system expects the elderly to be able to learn basic courses in addition to their interest and leisure courses, so as to get the knowledge and skills that are suitable for the life of the elderly. It encourages the elderly to learn and master certain skills and abilities of the society through the course, and can serve and influence the society autonomously, and ultimately achieve the self transcendence of life. 


\section{Development Trends of Elderly Education in the World}

In recent years, as an important means to practice the concept of lifelong learning and an important form to protect the learning right of the elderly, the education for the elderly with human rights protection and rational education for the elderly has been developing to the welfare oriented education for the elderly. Especially with the development of Internet technology, the forms and contents of the education for the elderly are constantly diversified and rich, showing the following new development trends and characteristics.

\subsection{Teaching Means: A New Trend of Online Learning for the Elderly}

The development of Internet technology has changed the form of education and learning. The construction of online learning environment can break through the barriers of time and space to send learning content to learners. It has changed the traditional way of learning from learners to learning providers, to the model of learning providers delivering learning to learners. However, this model has not received due attention for a long time. At the beginning of 2020, China encountered the severe challenge of COVID-19 epidemic situation, the traditional classroom education was fundamentally challenged, the offline curriculum of elderly education was also forced to stop, and the school running units of elderly education began to explore "online teaching". The epidemic situation has fully demonstrated the advantages of online education and online learning, accelerated the process of online education for the elderly, and further cultivated the online learning habits of the elderly. But its development potential is not limited to the response to the epidemic. The significance of online education is not only to supplement and enrich offline education. The integration of online education and offline education will become a normal, and online education for the elderly will also usher in new development opportunities.

\subsection{Participants: Mixed-Age Learning Becoming a Trend}

The so-called mixed age refers to that in the elderly education, the age of participants is not limited, and learners of different ages are allowed to participate. Mixed age is mainly based on the concept of well-being and promotes inter generational communication. It believes that society is a group of people of different ages and that people of different ages should contact and connect with each other. This is the norm of social existence. It is not appropriate to limit the elderly to a specific place or organization, so as to avoid the phenomenon of "subculture of the elderly" [5], which will increase the gap between different generations, create a sense of relative deprivation, and cause inter generational conflict. The development of learning activities for the elderly is mainly designed for the elderly. In the early stage, there are restrictions on their age. In the past, the most commonly adopted age limit in elderly learning activities in various countries is over 55 years old. In China, the participants of elderly education should reach 
the legal retirement age. This restriction on age was quite common in the past, but in recent years, it has been developing in the direction of "mixed age". For example, the third-age university in France has changed its name to mixed age university, National University and free time university. All restrictions on admission conditions have been cancelled, and it is open to the wider public. Courses and activities between generations have been set up to encourage exchanges among generations, so as to enhance mutual understanding among different generations. In fact, although the relevant courses of elderly education are mainly tailor-made for the elderly, the study of relevant courses is also necessary for people of different ages. Because the process of growing old is inevitable and irresistible. Therefore, the study of aging related courses should be implemented at different ages.

\subsection{Learning Place: Community-Based Learning Center for the Elderly}

The protagonist of learning for the elderly is the elderly. The scope of their daily activities and familiar things have been accumulated over the years, which is quite fixed and should conform to the habits, so the United Nations advocates the principle of "in localization" for elderly services. The learning place of the elderly is not limited to the classroom and facilities of the school, but also the place where the elderly activities themselves. Therefore, how to combine the learning in the classroom with the learning in the social contact area will become the focus of the elderly education. Grasping the principle of convenience, especially the activity space of the elderly, is mainly used by community public facilities. Especially, the elderly are slow or inconvenient in action. Learning activities should be designed with the community as the center, and the familiarity of the community location and members will enable the elderly to participate in learning, which is cohesive and sustainable. In terms of learning connotation, we should also grasp the spirit of community learning, pay attention to the unique needs of the community, the use of community resources, and the concern of community development issues, so as to combine community service with learning.

\subsection{Learning Style: Emphasis on the Autonomous Learning Model for the Elderly}

Learning emphasizes adaptive development. Only when it is suitable for individual needs and situations can it begin, and only if it is suitable for individual attributes can it be sustained and developed. The difference between the elderly is great, which is satisfied by the planning institutions and personnel. The most direct and effective strategy is to learn independently by the learners, and not to fight alone. But team work for organizational development and activities, is the role and function of autonomous learning groups. From the perspective of the past development of international advanced learning, autonomous learning groups play an important role and will certainly be an important hub for advanced 
learning in the future. In order to support learning for the elderly, the government must make good use of the strength of autonomous learning groups. The operation of autonomous learning groups is necessary for the implementation of community-based learning for the elderly. The professional development of elderly learning can also be achieved through the training and cooperation of autonomous learning groups. Autonomous Learning Group is a learner centered, through careful assessment of learning needs, integration of learning resources, to promote the full coordinated development of all kinds of learning, from understanding the needs, determining the object, activity implementation, to resource seeking, etc., it can consider the physical and mental development and lifestyle characteristics of participants, and make appropriate learning planning and implementation.

\section{The Characteristics and Advantages of Autonomous Learning Groups for the Elderly}

At present, the form of elderly education in China is still mainly traditional institutional education, and the form of autonomous learning prevailing in developed countries is still relatively rare in China. Autonomous learning group is a learner-centered, through careful evaluation of learners' needs, integration of educational resources, to promote the full and coordinated development of various educational resources, from understanding needs, determining objects, activities to resource seeking, can consider the physical and mental development of participants' life-form characteristics, appropriate educational planning and implementation. From the perspective of the development of geriatric education, autonomous learning groups play an important role and must be an important form of geriatric education in the future. This learning model has the following characteristics:

\subsection{Self-Operation, Self-Participation and Strong Learning Initiative}

All administrative and teaching works of autonomous learning groups are run by the members themselves. A new generation of elderly people has the ability to operate learning activities independently and prefer to carry out learning activities in this way. In the development of the third age university in Britain, the learning orientation of the elderly is self-help [6]. The new generation of elderly people is mature in physical and mental development, with self-directed personality characteristics, good health, high education, economic security, rich experience and various professional knowledge and ability. They are competent and efficient to serve as administrative work or teachers. They are also the group with the most free time and enthusiasm for service. They are eager to contribute light and heat continuously. Therefore, it is most appropriate for the elderly to operate their own learning activities. The participants of the autonomous learning group are all voluntary participants. They learn what they want to learn in 
their own way, which can best meet the learning needs of the elderly. The students have high participation, strong learning motivation and good natural learning effect. The members of self-regulated learning group are a group of learners with strong learning motivation. Their motivation is to seek new knowledge, expand their knowledge, and be practical in life. Their purpose is to develop their potential and realize themselves. It is a kind of satisfaction of personal internal psychological needs, not to obtain literature or qualification. Therefore, it does not have any external standard requirements such as evaluation, examination or achievement certification, Participants can participate in learning without threat. This kind of safe and warm learning atmosphere is a kind of pleasant enjoyment for the elderly. The elderly are most afraid of learning activities in a threatening atmosphere. Autonomous learning groups enable the elderly to have good interaction, happy sharing, warm atmosphere and high participation.

\subsection{No Qualification Restrictions for Participants}

Autonomous learning groups can participate as long as they have the will to learn, without any qualification restrictions. Therefore, the operation of autonomous learning groups is conducive to social integration and harmonious society. The most typical autonomous learning group in the world is the third age university in the UK. Although its courses are designed for the third age people, all kinds of people of different ages are welcome to join. When Britain developed the third age university in the early years, it established the principle that "the elderly are not a special ethnic group that can be separated from society" [7], so there is no qualification restriction in admission. There is no fixed site or building for autonomous learning groups. As long as there are people who want to learn, they can develop regardless of time and space and adapt to local conditions. Regardless of the learning method, place, time, content and so on, they can be flexibly adjusted according to the needs of local people, which can best adapt to regional differences. Autonomous learning groups can adapt to local conditions, people and times, and have economic effectiveness. Therefore, it can take root in various regions and achieve the effect of blooming everywhere. In the face of an aging society, this is a way to expand learning opportunities for the elderly.

\subsection{Cost-Effective, High Popularization Value}

At present, the elderly education in China is mainly is mainly run by institutions with large investment in funds and manpower. With the aggravation of the aging population, the scale and demand of the elderly education will expand rapidly, which will bring a certain burden to the government finance. From the experience of developed countries, the administration and teaching of autonomous learning groups are all held by members, which belongs to the nature of voluntary service and does not receive any fees. In addition, the venues and equipment 
are supported or borrowed from relevant local institutions or groups, so the funds required are quite low. For example, at the third-age university in the UK, students pay only 7 to 35 pounds a year. Although the government has a number of subsidies, the subsidy costs are small, and the costs are in principle borne by the members themselves [8]. Therefore, this is a relatively economic learning mode, which can be popularized.

\section{Exploration on the Elderly Education Model Based on Autonomous Learning Groups}

\subsection{Difficulties Faced by the Elderly Education under the Regular Situation of COVID-19 Epidemic Prevention and Control in China}

As an important means to carry out the concept of lifelong learning and an important form to guarantee the learning right of the elderly, the education for the elderly with human rights protection and rational education for the elderly has been developing to the welfare oriented education for the elderly. The forms and contents of the education for the elderly are constantly diversified and the contents are constantly enriched. In particular, the self-learning of the elderly is getting more and more attention. As far as the types of learning activities for the elderly are concerned, the types of learning activities for the aged in the world can be roughly divided into two types: institutional and autonomous. Obviously, in the current situation of COVID-19 epidemic prevention and control, autonomous learning model is more suitable for the development of elderly education in China. However, in China's elderly education system, the model of autonomous learning of the elderly has not played its due role, and the habit of autonomous learning of the elderly has not been generally formed. Specifically, there are the following problems in the current elderly education and learning:

1) The new model has not been established. The traditional education for the elderly is in a "stagnant" state, the way to improve the ability of the elderly to prevent and control the COVID-19 epidemic situation through formal learning in schools or institutions has been interrupted, the habit of autonomous learning of the elderly has not been formed, and the new learning mode has not been established.

2) Learning disorders are not cleared. Autonomous learning in the elderly is greatly affected by physical obstacles, environmental barriers and information barriers. Scientific methods are needed to reduce the impact of learning disabilities, which is also the key to carry out autonomous learning for the elderly.

3) Lack of professional guidance. The operation of autonomous learning groups for the elderly lacks corresponding experience, especially the model of using the Internet to carry out self-learning needs professional guidance.

In short, China's elderly learning implementation model needs to be innovated. In the past, the Ministry of education preferred institutional learning in the promotion of learning activities for the elderly, including open universities 
for the elderly, community universities, etc., but these learning resources are limited, far from meeting the huge learning needs of the elderly, and there are still barriers to participation for those who are inconvenient to move or do not like to participate in classroom learning. However, there is a lack of flexible autonomous learning. In addition, with the development of Internet plus technology and artificial intelligence, it is also urgent to develop information technology for providing mobile and intelligent learning resources for senior citizens. In other words, on the basis of the existing institutional learning, we should develop multiple learning modes and innovative learning forms, such as promoting autonomous learning groups for the elderly, or distance open learning mode, so as to create a high-quality learning environment for the elderly and help the elderly achieve the goal of active aging with richer platforms and contents.

\subsection{Path to Carry Out the Elderly Education Based on the Autonomous Learning Groups}

With the continuous development of aging in China, the postponement of the legal retirement age, the awakening of the people's awareness of aging, and the change of the concept of preventing old age, the traditional education for the elderly is facing challenges, and it must be changed to meet the needs of the education for the elderly in the new era. In order to meet the situation that the new generation of elderly people invests in education and learning continuously, the future education for the elderly must continue to innovate and develop.

1) Based on the elderly college students, set up online "autonomous learning group" to carry out course learning. Autonomous Learning Group is a learner centered group, through the assessment of learners' needs, the integration of educational resources, to promote the full coordinated development of various educational resources, from understanding the needs, determining the object, activity implementation to resource seeking. It can consider the life-form characteristics of participants' physical and mental development, and carry out appropriate educational planning and implementation. In the current situation, based on the existing classes of universities for the elderly and community universities, taking the curriculum as the core and nail-based online systems, we should set up online "autonomous learning groups for the elderly", and appoint students with a good professional foundation as group leaders. Organize and carry out online learning activities.

2) Taking the community as the unit, set up the community-based online "home-based learning group" to carry out community learning. Community is an important social field for the elderly, community clustering is the focus of current epidemic prevention and control, preventing the elderly community clustering should be one of the key points, the social needs of the elderly need to be correctly guided and transformed. Based on this, it is feasible to set up a community-based online "home learning group" to guide and transform offline social needs into online learning, sharing and social needs. 
3) Taking the family as the unit, set up the online "generation school house" to carry out mixed age learning. At present, the education for the elderly in developed countries generally advocates the implementation of mixed age education, and gradually abolishes the restrictions on the entrance conditions of the education for the elderly, and provides courses and activities between generations to encourage exchanges between generations, so as to enhance mutual understanding between different generations. Under the regular situation of COVID-19 epidemic prevention and control, the focus is to prevent close contact between people. Organizing family gatherings has become an important way to prevent and control the COVID-19 epidemic. However, the interaction between family and family is a realistic need. Based on the theory and practical needs of mixed age learning, this study advocates the establishment of online "families for generations" groups to carry out family type mixed age learning, which is also an important way to remove the environmental barriers that affect the learning of the elderly, and also meet the needs of family communication and communication.

\section{Conclusion}

With the continuous development of aging, the postponement of the legal retirement age, the awakening of people's awareness of aging, and the change of the concept of preventing old age, the traditional education for the elderly is facing more challenges, and it is necessary to make some changes to meet the needs of elderly education in the new era. Considering the situation that the new generation of the elderly invests in education and learning continuously, the future education for the elderly must be innovated and developed in the implementation mode, curriculum and teaching materials, teaching methods and contents, etc. At present, the form of elderly education is still mainly traditional institutional education, and the form of autonomous learning prevailing in developed countries is still relatively rare in China. Autonomous learning group is a learner-centered, through careful evaluation of learners' needs, integration of educational resources, to promote the full and coordinated development of various educational resources. From understanding needs, determining objects, implementing activities to seeking resources, this learning mode can consider the life-form characteristics of participants' physical and mental development, and carry out appropriate education planning and implementation. From the development trend of elderly education, autonomous learning groups play an important role and will be an important form of elderly education in the future. In order to support the elderly education, the government must make good use of the role of autonomous learning groups. By using the above strategies, we can develop the educational vision and development trend of the elderly society, and guide the future opportunities and efforts of the elderly education. Through the creation of a new era of lifelong learning environment, we can also develop the elderly people's greater potential and contribution, open the momentum of sus- 
tainable progress of the elderly society, and meet a new healthy and happy society for the elderly.

\section{Acknowledgements}

This paper is supported by "Epidemic Situation and Education" special project "Online Autonomous Learning Groups: A Study on the Elderly Education Model in the Period of COVID-19 Epidemic Prevention and Control" (2020YQJY006) and “The Mechanism and Empirical Research on Urban Elderly's Continuous Participation in Informal Learning Behavior in the New Era: Taking the Case of Zhejiang Province" (2020SCG240) of Zhejiang Education Science Planning in 2020. It is also the primary research results of the key project of the Ministry of Education of National Education Science Planning in 2019: "Research on the Realistic Dilemma and Optimization Path of Urban Elderly's Autonomous Learning in the New Era" (DKA190447) and general scientific research project (Y201942835) of Zhejiang Education Department in 2019.

\section{Conflicts of Interest}

The authors declare no conflicts of interest regarding the publication of this paper.

\section{References}

[1] XINHUANET.com (2018) There Are More than 60000 Universities and Schools for the Elderly in China. http://www.xinhuanet.com/politics/2018-12/26/c_1123907676.htm

[2] McClusky, H.Y. (1971) Education: Background paper for 1971 White House conference on aging.

[3] Londoner, C. (1978) Instrumental and Expressive Education: A Basis for Needs Assessment and Planning. In: Sherron, R.H. and Lumsden, D.B., Eds., Introduction to Educational Gerontology, Hemisphere, Washington DC.

[4] Wei, H.J. and Hu, M.G. (2010) Analysis of Curriculum of the Active Aging Learning Resource Centers: Application of McClusky's Margin Theory of Needs. Journal of Adult and Lifelong Education, 8, 115-150.

http://ericdata.com/tw/detail.aspx?no=26961

[5] Fischer L. (1978) The Concept of the Subculture of the Aging Reconsidered (Author's Transl). Aktuelle Gerontologie, 8, 661-665.

[6] Ellis, B. and Leahy, M. (2011) A Mutually Beneficial Relationship: University of the Third Age and a Regional University Campus. Gateways: International Journal of Community Research and Engagement, 4, 154-167. https://doi.org/10.5130/ijcre.v4i0.1787

[7] Lamdin, L. and Fugate, M. (1997) Elderlearning: New Frontier in an Aging Society. Oryx Press, Phoenix, AZ.

[8] Huang, F.S. and Lin, L.H. (2017) The Development and Prospect of Taiwan's Elderly Autonomous Learning Groups. Education Research Monthly, 11, 41-54. 